\title{
Gestão de Orçamento Familiar
}

\author{
Alexandre da Silva Viegas \\ Bacharelado em Ciências Contábeis pelo Instituto de Ensino Superior de João \\ Monlevade - IES / FUNCEC \\ Contador da empresa Logística da Vale \\ Rua das Margaridas, 55. Residencial Santo Antônio. Santa Bárbara/MG \\ E-mail: alexandre.viegas@vale.com \\ José do Carmo Pinto \\ Pós-Graduando em Gestão Empresarial pelo IES/FUNCESI \\ Rua Maranhão, 281. Bairro Satélite. João Monlevade/MG. CEP: 35.930-254 \\ E-mail: jose.carmo@arcelor.com.br \\ Mestrado em Administração pela Faculdades Integradas Pedro Leopoldo - Unipel \\ Professor Titular do Instituto de Ensino Superior de João \\ Monlevade, IES/FUNCEC \\ Rua Viçosa, 611. Belmonte. João Monlevade/MG. CEP: 35930-309 \\ E-mail: pedroxavier@funcec.br
}

\section{RESUMO}

O objetivo deste trabalho é apresentar um levantamento das funções administrativas e verificar a possibilidade de aplicação na micro entidade denominada de família. Aborda a utilização das funções administrativas, principalmente, o planejamento, a organização e o controle, como meios para o gestor familiar acompanhar a variação da riqueza do patrimônio. Procurou-se conhecer o perfil de famílias de uma cidade mineira, evidenciando suas opiniões a respeito da gestão familiar e, principalmente, da utilização de controle das despesas e custos, evitando ter uma saída de recursos excedente às entradas. Utilizou-se de estudo bibliográfico e pesquisa de campo. A consolidação da gestão familiar baseia-se, especialmente, no interesse dos gestores, na mudança de comportamento, na visão de médio e longo prazo, enfim na efetivação de um orçamento familiar que atenda as necessidades do imediatismo e na elaboração de um planejamento estratégico que vise a maximização do patrimônio familiar tangível e intangível.

Palavras-chaves: Família. Funções administrativas. Controle.

\section{Management of Budget Family}

\section{ABSTRACT}

The objective of this paper is to present records of administrative functions and check the possibility to apply them on the micro organization, called family. It approaches the use of 
the administrative functions such as, planning, organization, and some controls such as ways to control the family wealth. It searches the profile of the cities located in the Minas Gerais state, recording their opinions regarding the family management, and mainly the use of the income and outcome, avoiding having an outcome greater than an income. It was used literature review and survey in the cities. The consolidation of the family management is based mainly on the managers' interest, behavior changes, and medium and long term view. In other words, it is based on a family budget which fulfill the immediate needs and on the creation of a strategic plan which aim at the maximization of the tangible and intangible family properties.

Key Words: Family. Administrative Functions. Control.

\section{INTRODUÇÃO}

O cenário econômico e social em que vivemos é muito dinâmico. As mudanças ocorrem a cada dia com maior velocidade. Para acompanhar tal velocidade e agir de forma pró - ativa, é preciso abandonar posições cômodas e antecipar as tomadas de decisões. Tal estratégia não se restringe somente às organizações empresariais, faz-se necessária nas pequenas células sociais como, por exemplo, a família.

A família é a primeira e mais importante sociedade organizada do mundo, além de ser a base de todas as outras sociedades. Por tamanha importância, é considerada como a principal unidade básica de desenvolvimento pessoal a que pertence um indivíduo e o local onde se vivencia um conjunto de experiências fundamentais para a formação de personalidades. É na família, por sua qualidade de gestora da vida, que o ser humano nasce e cresce.

Como as demais entidades, a família possui um patrimônio e deve se preocupar com o controle do mesmo visando acompanhar a variação de sua riqueza. $\mathrm{Na}$ família, constituída através da reunião de duas ou mais pessoas, além dos aspectos sentimentais que as ligam, outros interesses devem estar presentes para suprir necessidades econômicas e de tomada de decisão quando duas ou mais alternativas se apresentam.

A família não pode ficar indiferente quanto à necessidade de se implantar controles dos ganhos e, principalmente, dos gastos para a continuidade do patrimônio familiar. Como uma célula social, precisa utilizar a organização, o planejamento e o controle, 
independente do número de espécimes que a constitui.

Para essa entidade, entendemos que não há necessidade de separação dos conceitos de gastos, despesas e custos. Consideramos que as despesas ou os custos familiares serão as saídas de recursos para satisfazer as necessidades das famílias, logo não há a preocupação em conhecer o que pertence ou não ao processo produtivo, como nas indústrias. A família pode ser considerada como uma entidade social, na qual não existe produção de bens e serviços, e sim origem e formação do capital humano, principal ativo das demais entidades que compõem a sociedade. Como as demais entidades, a família possui um patrimônio e deve se preocupar com o controle do mesmo visando acompanhar a variação de sua riqueza.

As condições da família dependem de fatores como o número e características de seus componentes (sexo, idade, instrução, nível de qualificação, etc) e de sua posição hierárquica no grupo (chefe, cônjuge, filhos, etc), onde estão associados papéis definidos socialmente. O IBGE (2006), no Censo de 2000 retrata que

famílias com filhos mais novos ou chefiadas por mulheres possuem maior probabilidade de serem pobres ou muito pobres. Entretanto, à medida que os filhos crescem e começam a entrar no mercado de trabalho, essa probabilidade diminui, vindo a crescer novamente em algum momento na família de chefes idosos, seja quando ainda há filhos maduros em casa, seja quando o casal ou o cônjuge se torna viúvo.

Como qualquer outra sociedade, a família deve ser gerida e estruturada para atingir os seus objetivos emocionais, sociais, financeiros e econômicos. Foi o pensamento sobre o futuro que levou o homem aos primeiros registros para conhecer as suas reais possibilidades de uso, de consumo, de produção, etc. Com o surgimento das primeiras administrações particulares aparecia a necessidade de controle, que não poderia ser feito sem o devido registro, a fim de que se pudesse prestar contas da coisa administrada.

\section{PATRIMÔNIO, PATRIMÔNIO FAMILIAR E ORGANIZAÇÃO}


O patrimônio pode ser conceituado, contabilmente, como o conjunto de bens, direitos e obrigações pertencentes a uma pessoa jurídica ou física. No ambiente familiar verificamos a presença destes elementos. Os bens são necessários para que a família viva. Representam os bens móveis, imóveis, de consumo e outros. Os direitos figuram como créditos que a família tem com terceiros, como salário a receber, empréstimos a receber, fundo de garantia a receber, etc. As obrigações são as dívidas da família; o compromisso de pagamento dos serviços públicos utilizados, empréstimos a pagar, mensalidades a pagar, juros a pagar, etc. De acordo com Sá (2002, p.62),

o patrimônio origina-se de fontes que criam o mesmo, representando sua contrasubstância, ou seja, os financiamentos, suportes próprios, dotações e resultados que dão condições para que possa existir a riqueza. Tais fontes são as que dão oportunidade, também de formar a substância, ou seja, são causas da existência do que poderíamos dizer também "corpo da riqueza".

Com a família não é diferente. Seus objetos materiais, os conhecimentos adquiridos, as reservas financeiras, são de sua propriedade e consequentemente constituem seu patrimônio.

A contabilidade é um instrumento de grande utilidade na organização e controle do patrimônio familiar, visto que seus elementos se encaixam eficientemente dentro das finanças de uma família. Uma das maiores dificuldades de controle que se tem hoje, é fazer o equilíbrio do orçamento doméstico das entradas e saídas de recursos. Muitas pessoas não têm a mais vaga ideia do patrimônio que possuem, do volume das suas despesas mensais e de quanto precisam por mês para viver confortavelmente.

Para equilibrar o orçamento e fazer com que as despesas se tornem menor do que as receitas (no caso, salário), é preciso analisar se os gastos variáveis (alimentação, luz, água, telefone, etc) e arbitrários (viagens, roupas, restaurante, etc), podem ser reduzidos. Pode ser o princípio de uma boa economia. Geralmente, os gastos arbitrários são aqueles que podem ser cortados da noite para o dia e que farão pouca diferença no cotidiano. O ideal é cortá-los primeiro e à medida que se for organizando as finanças eles poderão ser colocados novamente aos poucos dentro do orçamento.

Outra alternativa é o gestor familiar buscar formas de aumentar suas receitas, 
porém, verificamos que pode levar um tempo para sua efetivação. Enquanto estiverem com as despesas maiores que as receitas, seria conveniente atuar nestes gastos controláveis, afinal o aumento da receita dependerá do ambiente externo. Podemos comparar com a formação do preço de venda, no qual não implicam apenas os custos empresarias, mas a conjuntura do mercado. Logo se os custos forem maiores que os valores de venda praticados no mercado, o gestor deverá dar ênfase à redução de custos (ambiente interno) e depois procurar aumentar suas receitas, através de um maior volume de vendas e de novos nichos.

Segundo Maximiano (1995, p.25),

uma organização é uma combinação de esforços individuais que tem por finalidade realizar propósitos coletivos. Por meio de uma organização torna-se possível perseguir e alcançar objetivos que seriam inatingíveis para uma pessoa. Uma grande empresa ou uma pequena oficina, um laboratório ou o corpo de bombeiros, um hospital ou uma escola são todos exemplos de organizações.

Uma organização é formada pelo somatório de pessoas, máquinas e outros equipamentos, recursos financeiros e outros. A organização então é o resultado da combinação de todos estes elementos orientados a um objetivo comum.

No meio familiar não é diferente, quanto maior o nível de organização, maior será a facilidade para administrar o seu patrimônio. A organização dos bens e direitos, das receitas, das obrigações, das despesas, pode auxiliar o gestor da família no controle e maximização do seu patrimônio.

\section{GESTÃO E GESTÃO FAMILIAR}

O conceito da gestão, apesar de largamente difundido, não constitui um consenso. Inúmeras são as suas fórmulas e propostas que vêm ganhando estrutura e conteúdo desde os primórdios da administração, tanto pública, quanto privada. Assim, sem a preocupação de apresentar cada passo de sua evolução, basta que seja observada a sequência das escolas clássicas da administração para identificar e concluir sobre o amplo leque de conceitos distintos, às vezes contraditórios, que já 
receberam o rótulo de gestão.

Entretanto, a gestão pode ser conceituada através dos elementos que precisam estar presentes em sua prática. Dessa forma pode-se conceituar a gestão como sendo um processo sistemático e permanente que envolve o planejamento da ação, a implantação da ação, a manutenção da ação, os registros das atividades envolvidas, o registro dos resultados previstos e alcançados, a documentação das decisões e atividades decorrentes, a disseminação de informações de relevante interesse, a monitoração dos processos e atividades, a monitoração do desempenho organizacional interno e externo, o controle dos processos e dos resultados, a avaliação crítica de todos os elementos da gestão, e o aprimoramento contínuo dos mesmos.

Poucos são os estudos que tratam da gestão familiar, entretanto, parece razoável supor que a mesma deve adotar critérios semelhantes aos utilizados em uma entidade empresarial. Nas famílias de classe média e aquelas consideradas ricas, verifica-se a importância da organização de uma contabilidade; impõe-se essa necessidade, quando existe mais apreciável estado de fortuna e quando sejam mais intensas as atividades econômicas.

\section{PLANEJAMENTO, ORÇAMENTO E CONTROLE FAMILIAR}

O planejamento, junto com a organização, poderia ser considerado o primeiro degrau na consecução dos objetivos familiares. O processo de planejar requer um modo de pensar que envolve interesses, indagações; e estas envolvem questionamentos sobre que será feito, como, para quem, quando, por que, por quem e onde será feito. Conforme Halfeld (2004, p.25), todos são capazes de modificar o comportamento. $\mathrm{O}$ autor menciona que

talvez a mudança de pequenos hábitos possa gerar importantes contribuições em sua poupança. Talvez tal mudança signifique uma aposentadoria alguns anos mais cedo. Pense nisso... Cada um tem um estilo de vida e deve saber escolher onde gastar seu suado dinheiro. Poupar é a primeira batalha investir corretamente, fazendo seu dinheiro crescer, é a segunda. Usufruir dos resultados obtidos é vencer a guerra. 
Oliveira (1997 in FRAGA, 2005, p.20) menciona a opinião de Drucker a respeito do planejamento, enfatizando que o mesmo não diz respeito a decisões futuras, mas às implicações futuras de decisões presentes. O gestor familiar deve estabelecer suas metas abrangendo eventos presentes e futuros, visando à sustentação, prosperidade $e$ economicidade do patrimônio.

O planejamento é o conjunto previamente ordenado de ações que têm como fim alcançar posições futuras desejadas. Compreende o envolvimento de pessoas, a alocação de recursos e procedimentos de controle e avaliação necessários para estimar a efetividade das ações em relação ao que foi estabelecido. Refere-se a uma estimativa de impacto no futuro das ações adotadas no presente. Alguns tipos de planejamento são os referentes à: de longo prazo; dos investimentos de capital; orçamentário, etc.

O produto final do planejamento é a orientação sobre o impacto das decisões que devemos tomar hoje. O planejamento é afetado por múltiplos fatores e recursos que se entrecruzam no sentido de retratar e abranger diferentes perspectivas. Ressalta-se, entre essas, o desafio de se estabelecer uma coerência entre os objetivos e os meios para alcançá-los. De acordo com Kontz (1959, p.87),

o planejamento é a mais fundamental das cinco funções administrativas, de vez que envolve seleção dentre cursos alternativos de ação para a empresa, como um todo, e para cada departamento e pessoas que a integram. O planejamento não é somente uma função básica para todos os administradores em todos os níveis da empresa, como ainda as quatro outras funções do administrador dele dependem. Assim é que um administrador organiza, designa pessoal, dirige e controla para assegurar a consecução de objetivos em conformidade com os planos.

O planejamento envolve a seleção de objetivos da empresa bem como metas departamentais e de programas e a determinação dos meios para atingi-los. Constitui, pois, a elaboração de uma abordagem racional para objetivos e metas parciais pré-escolhidos. De vez que esta abordagem não tem lugar num vácuo, o bom planejamento tem de considerar a natureza do futuro em que as decisões e ações planejadas devem operar.

A amplitude do planejamento pode ser ilustrada pelos tipos de planos que a 
empresa possui. Eles podem ser classificados como:

- Objetivos ou metas: são fins para os quais se dirige a atividade;

- Diretrizes: orientam ou canalizam o raciocínio no processo de tomada de decisão pelos subordinados;

- Procedimentos: estabelecem um método costumeiro de lidar com as atividades futuras;

- Normas: constituem um curso de ação necessário;

- Orçamentos: são uma afirmação de resultados esperados;

- Programas: são um complexo de diretrizes, procedimentos, normas, designação de obrigações, e outros elementos necessários para dar andamento a um certo curso de ação;

- Estratégias: são consideradas como planejamento interpretativo, ou planos feitos à luz dos planos de um competidor.

A revisão bibliográfica do tema planejamento possibilitou aos autores deste trabalho a verificação de que esta teoria pode ser aplicada ao ambiente familiar, logo, adaptou-se à mesma e chegou-se ao Planejamento do Orçamento Familiar (POF).

O POF deve ser bem detalhado em todos os segmentos. Nele deverão constar todas as fontes de renda da família, bem como as despesas/custos. É onde se busca o equilíbrio entre receitas e despesas, o qual mostrará o que é supérfluo e o que é básico, norteando assim a estratégia de gestão do patrimônio da família.

Orçamento familiar é a relação entre a soma das receitas (salário, pensões, etc) e dos gastos mensais. É importante saber se a renda é regular (quando se recebe mensalmente na data certa) ou irregular (quando não há certeza da quantia recebida). Deve-se ter uma ideia da receita do mês e daquilo que se pretende gastar. As despesas/custos podem ser separadas por categorias conforme exemplificado a seguir:

- Alimentação: Supermercado, padaria, açougue.

- Habitação: Aluguel, condomínio, água, luz, etc. 
- Vestuário: Roupas, sapatos, acessórios.

- Educação: Mensalidades, material escolar.

- Saúde: Médico, dentista, remédios.

- Higiene: Higiene pessoal, produtos de limpeza.

- Transporte: Ônibus, combustível, gasolina.

- Serviços: Faxineiro, cabeleireiro, manicure, costureira.

- Lazer: Férias, passeios, festas.

O orçamento familiar não se resume apenas em "anotar as despesas realizadas". Envolve planejamento, priorização e controle do fluxo de caixa. É o que orienta o Financenter (2006):

a elaboração do orçamento familiar não é uma tarefa fácil, porém, é necessária para quem tem planos para o seu futuro e o de sua família. Estabelecer objetivos comuns e conversar francamente sobre as finanças com a família é o caminho para que cada um esteja comprometido e faça sua parte. É a forma de garantir a estabilidade das finanças no presente, visando prevenir o futuro.

Outro ponto importante na gestão familiar e que podemos considerar como base do orçamento e do planejamento é o controle. O mesmo significa acompanhar e/ou atuar no processo de maneira que os seus efeitos estejam em conformidade com padrões (metas) estabelecidos. O controle é exercido para manter os resultados ou para melhorá-los. Controle equivale à administração, gerência. Controlar é monitorar os resultados e buscar as causas (meios) da impossibilidade de se atingir uma meta (fim), estabelecer contramedidas e/ou montar um plano de ação, atuar e padronizar em caso de sucesso.

O controle faz com que os fatos se conformem aos planos. Depois de traçada uma meta e elaborados os controles para atingir os objetivos, deve-se verificar a execução dos mesmos e/ou aperfeiçoá-los. Recorrendo a D’Áurea (1957, p.110) sobre a importância do controle do patrimônio familiar, é possível confirmar que investimentos, e ao pensarmos neles devemos nos lembrar que investir significa adiar um consumo presente, para 
no futuro ter mais dinheiro para consumir. A análise de investimento empresarial pode atender aos seguintes objetivos:

- Definir dentre vários projetos de investimento qual o mais rentável;

- Calcular a rentabilidade de um determinado projeto de investimento;

- Determinar o volume mínimo de vendas que um projeto de investimento precisa gerar para que possa ser rentável; e

- Definir o tamanho ideal de um projeto de investimento.

Ao organizar as finanças familiares com critérios definidos, sendo bastante realista com as receitas e despesas, é possível descobrir que se têm mais recursos do que se imagina para fazer aplicações. Ao definir os objetivos de investimentos, a decisão deve levar em consideração os prazos de retorno, conforme descrito a seguir:

a) Objetivos de curto prazo: são aqueles que se deseja alcançar em até um ano. São aplicações para ter um fundo de emergência, para financiar suas próprias férias ou algo do gênero.

b) Objetivos de médio prazo: são aqueles que se levam de um a cinco anos para conquistar. Esses investimentos servirão para compra da casa própria, troca do carro, etc.

c) Objetivos de longo prazo: são aqueles destinados, por exemplo, à complementação da aposentadoria ou à faculdade dos filhos, pois espera-se que se comece a pensar sobre isso com mais de cinco anos de antecedência.

Segundo Luquet (2002, p.20),

o prazo de seu investimento é um item importante a ser considerado quando você estiver avaliando o risco de sua aplicação. Se você tem tempo, as aplicações de maior risco tendem a dar uma rentabilidade mais atraente do que aplicações conservadoras. Já opções muito conservadoras, como a caderneta de poupança, podem, no longo prazo, levá-lo a perder dinheiro. 
Outra forma de selecionar os objetivos é dividi-los em duas categorias: preservação ou aumento do capital. Se a intenção é apenas preservar o capital, deve-se deixar o dinheiro em aplicações de renda fixa. Mas se o objetivo é ter um aumento do capital investido, a opção é deixar uma parcela do dinheiro em aplicações de maior risco como ações, que podem fazer o patrimônio crescer no longo prazo.

\section{MÉTODO DE PESQUISA}

Para realização da pesquisa de campo escolheu-se a cidade de João Monlevade em Minas Gerais. Conforme o censo do Instituto Brasileiro de Geografia e Estatística (IBGE, 2006) - censo de 2000, o município de João Monlevade possuía 66.690 habitantes e cada família era composta por 3,8 pessoas. A partir destas informações obteve-se a população para a realização dos cálculos amostrais, que é 17.550 famílias (66.690 $3,8)$.

Definiu-se pela margem de erro de $5,5 \%$ e o coeficiente de confiabilidade de $95 \%$, visando à obtenção de uma amostra estatisticamente relevante e cujo resultado atendesse aos anseios da pesquisa. A fórmula abaixo foi utilizada para estabelecimento do tamanho da amostra:

$$
n=\frac{1,96^{2} \cdot 0,5 \cdot 0,5 \cdot 17 \cdot 550}{(0,055)^{2} \cdot(17 \cdot 550-1)+1,96^{2} \cdot 0,5 \cdot 0,5}=312
$$

Conforme o desenvolvimento da fórmula, chegamos à conclusão que o número mínimo de retorno deveria ser de 312 questionários para tornar os resultados da pesquisa generalizáveis.

Pesquisou-se de executivos a funcionários braçais dos diversos segmentos. Não houve segregação dos indivíduos por padrões ou classes sócio-econômicas. Partiu-se do pressuposto que um modelo de gestão deve estar voltado para atender às necessidades dos diversos tipos de famílias, independente do tamanho do seu patrimônio.

Os dados foram organizados e classificados de acordo com a coleta obedecendo à região, a faixa etária, a renda, etc, visando proporcionar informações que sejam de fácil 
entendimento tanto aos participantes do projeto, quanto aos estudiosos do assunto. A apresentação dos dados se deu através de gráficos e planilhas visando melhor entendimento.

Como o total de questionários respondidos foi de 321 e o número mínimo apontado pelo cálculo amostral de 312, verifica-se um desempenho de 102,88\% (321/312 x 100) na aplicação da pesquisa.

\subsection{Análise dos dados e resultado da pesquisa}

Os dados foram coletados por meio de questionários aplicados diretamente pelos autores do artigo. Os resultados apurados estão examinados na sequência.

1) Quantidade de pessoas na família que contribuem para a renda mensal

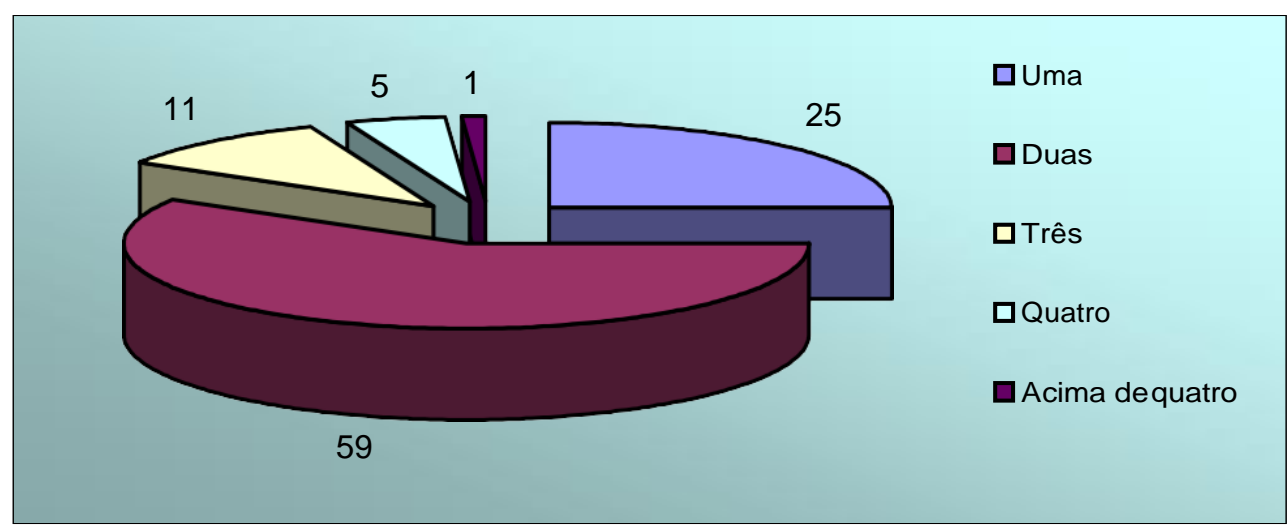

Figura 1 - Número de pessoas na família que contribuem para a renda mensal

$\mathrm{Na}$ maioria das famílias, ou seja, em $75 \%$ delas há duas ou mais pessoas contribuindo para a renda mensal.

2) Nível de escolaridade das pessoas da família que contribuem para a renda mensal 


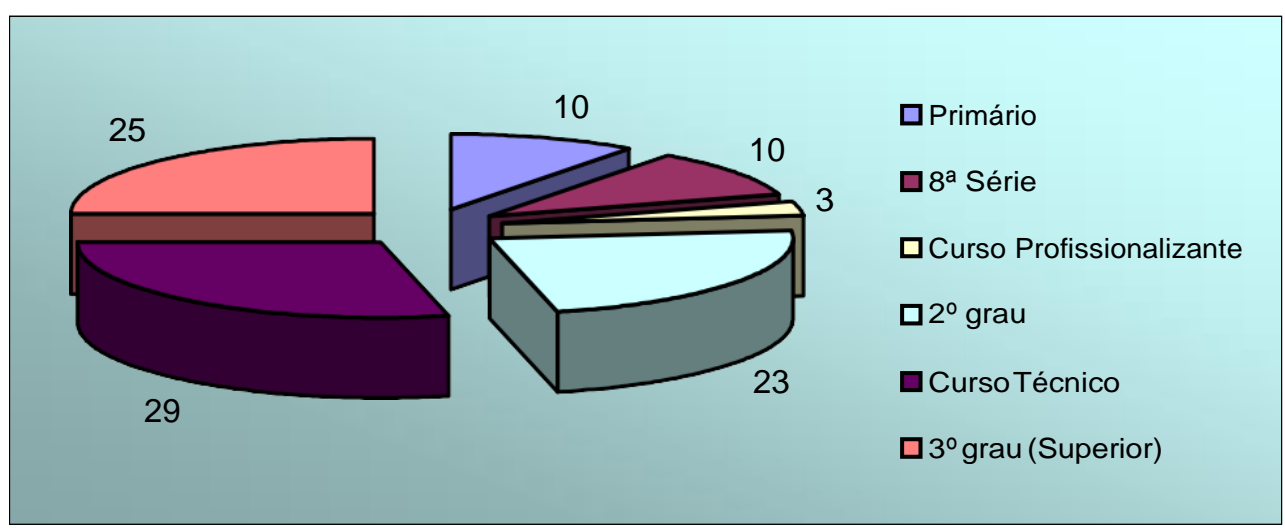

Figura 2 - Nível de escolaridade dos que contribuem para a renda mensal

A maioria dos entrevistados, ou seja, $52 \%$ deles possuem segundo grau ou curso técnico. Já os formados em nível superior totalizam $25 \%$.

\section{3) Renda familiar mensal}

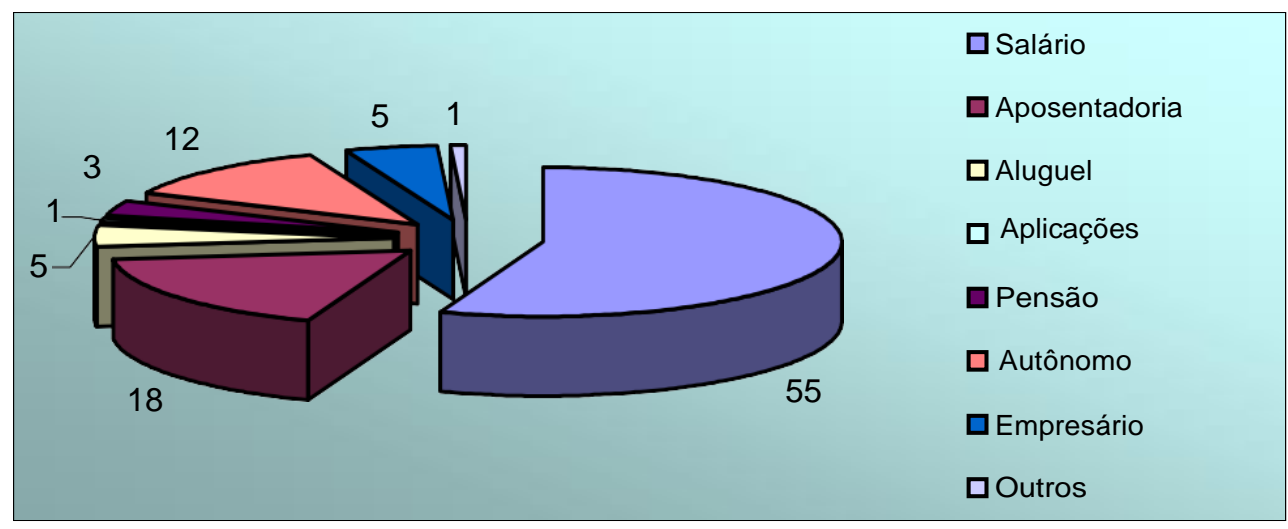

Figura 3 - Formação da renda familiar

De acordo com o gráfico acima, verifica-se que a maioria, ou seja, $55 \%$ dos entrevistados são assalariados, já os que trabalham por conta própria (autônomos e empresários) totalizam $30 \%$.

\section{4) Faixa da renda familiar mensal}




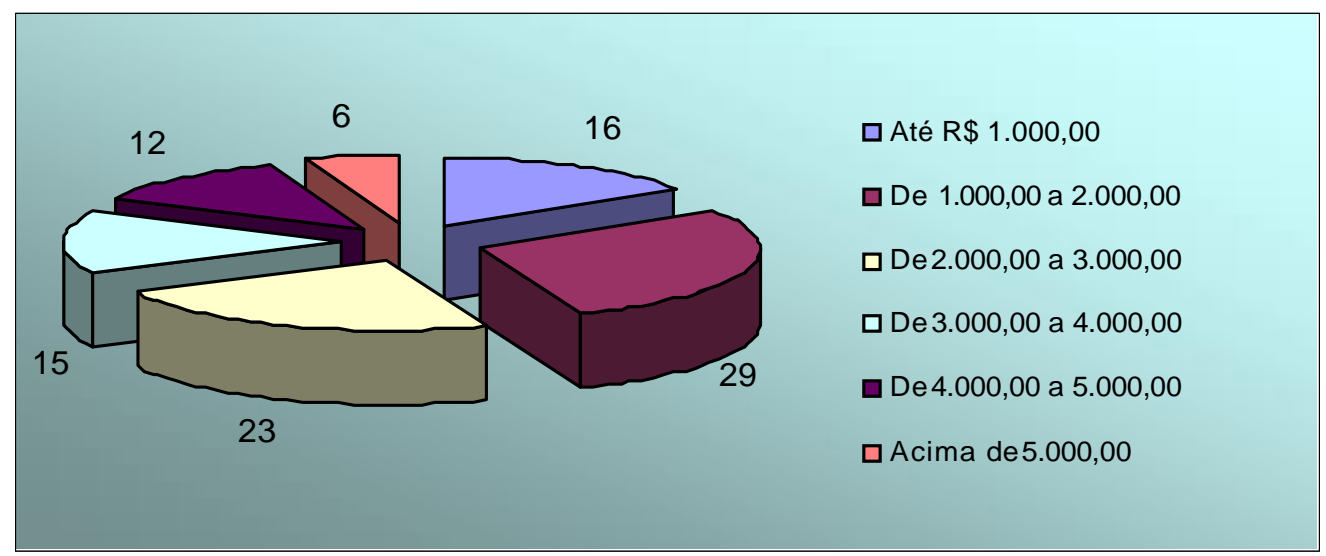

Figura 4 - Faixa da renda familiar mensal

Nota-se pelo gráfico que $45 \%$ dos entrevistados possuem renda familiar mensal de até $R \$ 2.000,00$. Já as famílias com valores entre $R \$ 2.000,00$ e $R \$ 4.000,00$ totalizam $38 \%$ dos entrevistados. Apenas $18 \%$ dos entrevistados possuem renda superior $\mathrm{R} \$ 4.000,00 / \mathrm{mês}$.

\section{5) Planejamento ou controle entre renda e despesa}

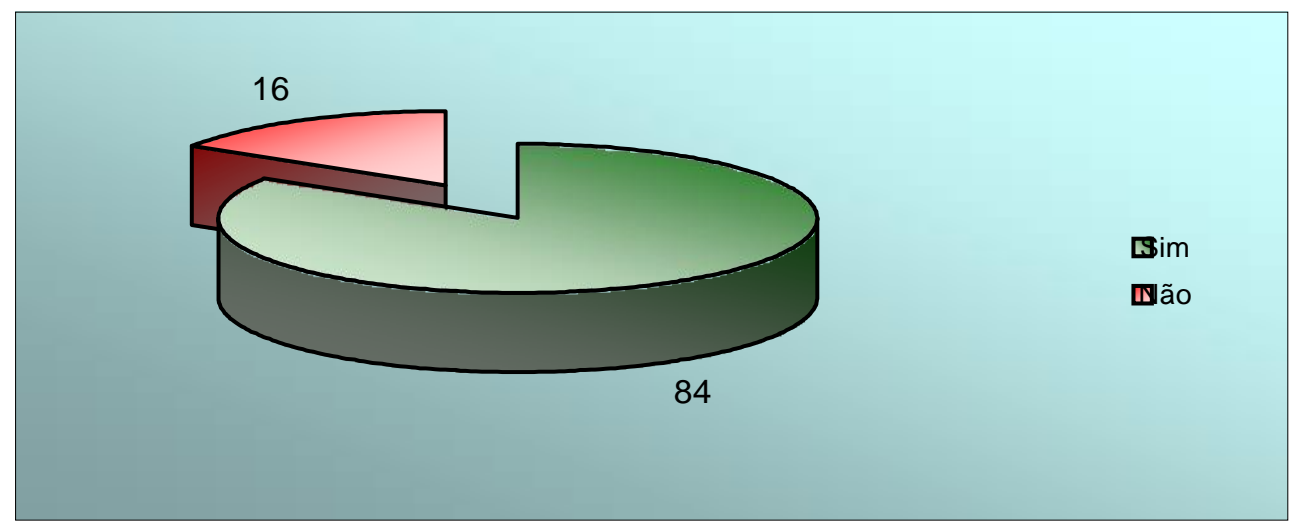

Figura 5 - Planejamento ou controle entre renda e despesa

A grande maioria dos entrevistados, ou seja, $84 \%$ deles, responderam que fazem algum tipo de controle entre o que ganham e o que gastam.

$\mathrm{Na}$ mesma questão, para os que não fazem nenhum controle, foi perguntado o motivo porque não o fazem. As opções "falta de tempo" e "falta de conhecimento" tiveram resultado bem semelhantes, já que as respostas foram $28 \%$ e $25 \%$, respectivamente. Já 
opção "acha que não precisa" obteve maior votação com $34 \%$ dos entrevistados.

\section{6) Periodicidade do controle entre renda e despesa}

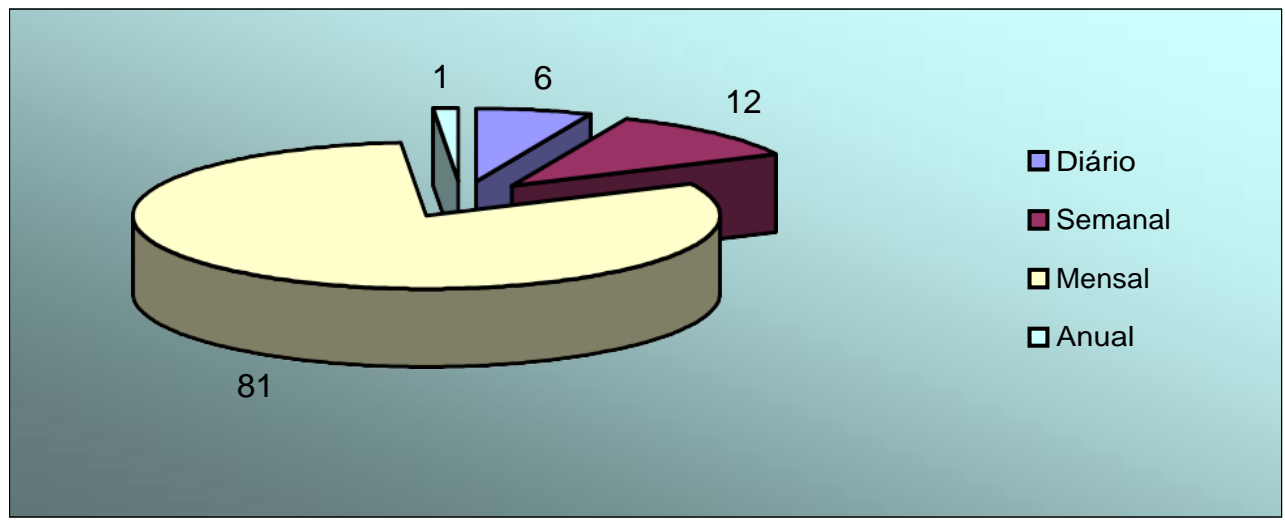

Figura 6 - Periodicidade do controle entre renda e despesas

A grande maioria, ou seja, $81 \%$ dos entrevistados fazem o controle entre o que ganham e que gastam mensalmente.

7) Credibilidade da realização do controle entre renda e despesa

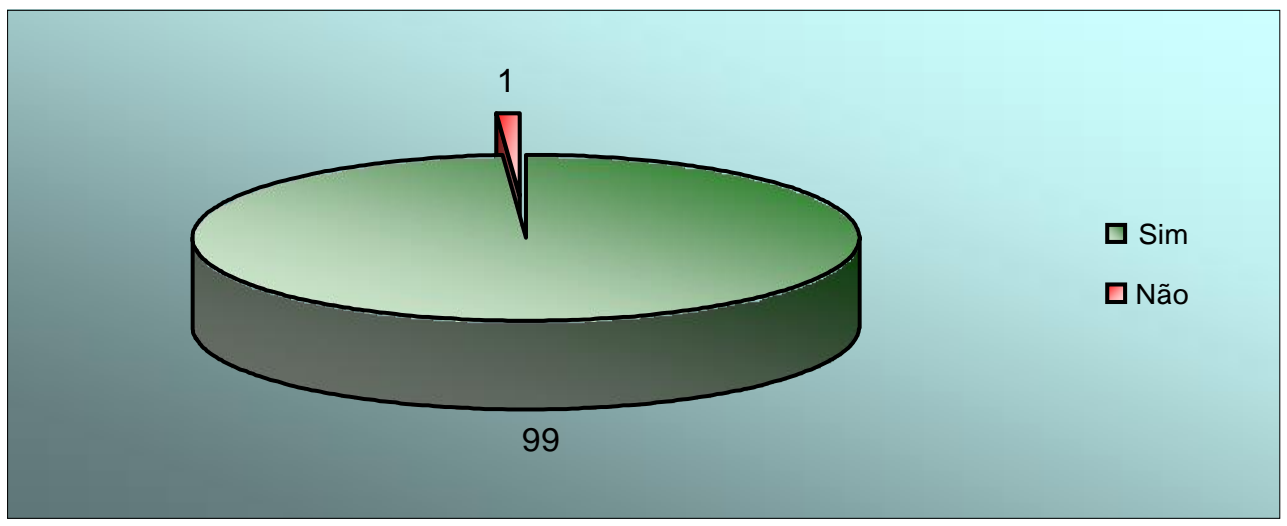

Figura 7 - Credibilidade da realização do controle entre renda e despesa

Como pode ser notado, praticamente todos os entrevistados, ou seja, $99 \%$ responderam que acreditam que o controle financeiro pode evitar problemas futuros.

Os resultados da pesquisa revelam que há espaço para se tentar contribuir para que as famílias tenham um maior controle em seu orçamento. Diante disso, na próxima 
seção apresentamos um "modelo de orçamento familiar".

\subsection{Modelo de orçamento familiar}

O planejamento financeiro é essencial para administrar o dinheiro. Administrar as finanças de forma aleatória e conforme as ocorrências do dia-a-dia poderá levar a família à dificuldades, inclusive as básicas. O controle dos gastos é fundamental para a manutenção de um orçamento familiar equilibrado. É preciso organizar o tempo e se dedicar semanalmente à verificação das entradas e saídas de recursos.

Outro ponto importante do planejamento financeiro é o fato de induzir a previsão de percalços que podem ocorrer na vida familiar como, por exemplo, doenças, acidentes, desemprego, morte, etc.

Embasado em diversos sites de finanças abordados no referencial teórico, os quais disponibilizam vários modelos de controles para as pessoas físicas e, tendo por objetivo auxiliar na gestão financeira, elaborou-se uma proposta de controle que possa atender às necessidades de acompanhamento da evolução econômica das famílias. Levou-se em consideração a simplicidade, a aplicabilidade e a compreensibilidade, buscando facilitar a utilização por uma pessoa completamente leiga no assunto de controle. Utilizou-se a ferramenta excel para a estrutura do controle, conforme figura a seguir.

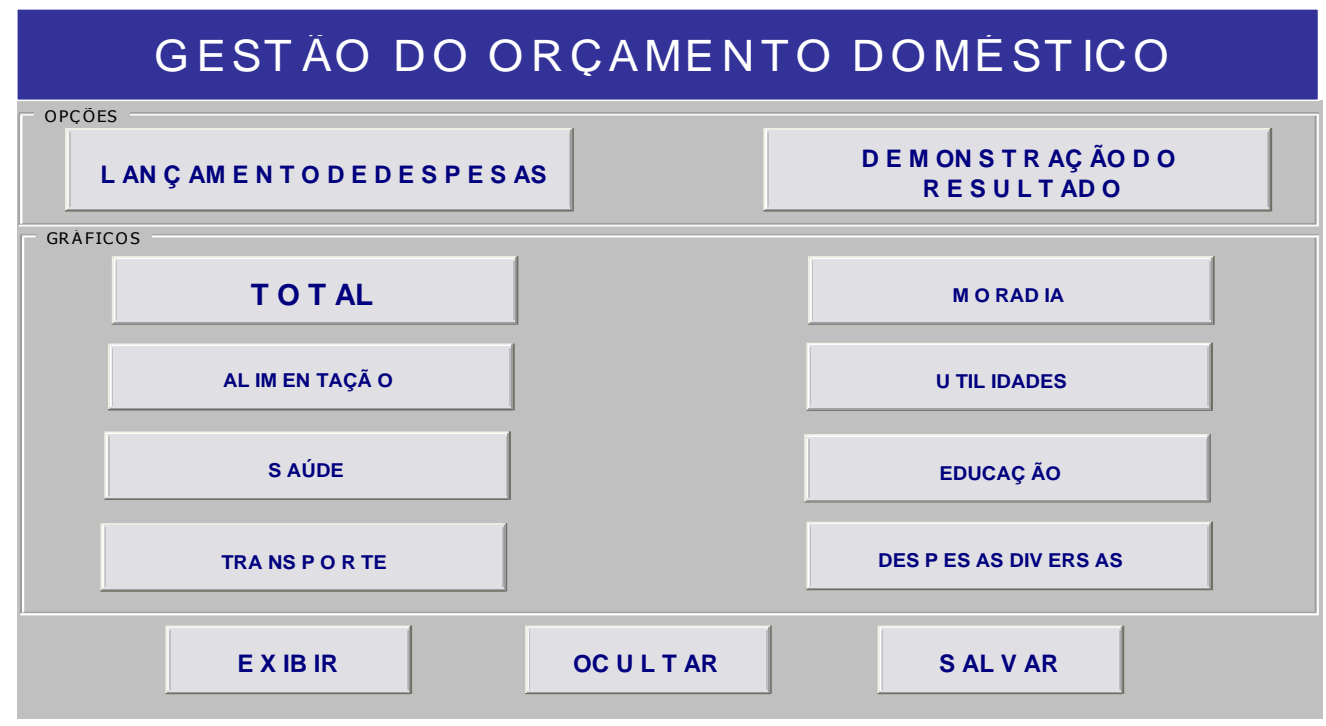


No item 'lançamento de despesas' tem-se todos os gastos familiares: alimentação, saúde, transporte, moradia, utilidades, educação e despesas diversas. As mesmas, automaticamente, irão para a Demonstração do Resultado possibilitando verificar as Receitas menos as Despesas e apurando o resultado do período. Após essas operações, será possível visualizar o gráfico de cada despesa, bem como o geral.

\section{CONSIDERAÇÕES}

A família é considerada desde os primórdios a célula social núcleo da sociedade. É responsável pela formação do capital humano, considerado por alguns autores como o principal ativo de outras células sociais maiores. É também de suma importância no cenário econômico, atuando como uma unidade consumidora de bens e serviços e agregando valor.

A análise global do resultado da pesquisa de campo possibilitou verificar, de um modo geral, que as pessoas têm consciência da importância e da necessidade de se fazer o controle da gestão familiar e, quando não o fazem, é principalmente pela falta de hábito para dedicarem tempo a essa questão ou por falta de conhecimento.

Para efetivar os controles é necessário que a verificação das informações ou do orçamento seja feita semanalmente, e as anotações sobre as despesas, principalmente, feitas diariamente como num fluxo de caixa. Destaca-se há pouca bibliografia no Brasil a respeito da gestão familiar. Entretanto, criar uma cultura de aprender a controlar precocemente os ingressos e desembolsos pessoais, é uma alternativa para que se transmita esse conhecimento às gerações futuras. Para isto, é fundamental que as pessoas mudem comportamentos, atitudes, tenham uma visão de futuro, tornando como rotina a utilização de controles na gestão do patrimônio familiar.

Apesar da existência de vários modelos de controle, a sua aplicação é escassa e, quando feita, geralmente se restringe a simples anotações. É preciso ensinar o porquê, é preciso analisar as causas que levam as famílias ao descontrole, principalmente, o financeiro. 


\section{REFERÊNCIAS BIBIOGRÁFICAS}

CHIAVENATO, I. 1993. Teoria da Administração. São Paulo, Makron, 4ae ed., 920 p.

D`AUREA, F. 1957. Organização e Contabilidade patrimonial Doméstica, São Paulo, Nacional, 189 p. FRAGA, M.S. 2005. Controle na gestão do patrimônio familiar. Salvador, Bahia. Dissertação de Mestrado. Fundação Visconde de Cairu. $115 f$.

HALFELD, M. 2004. Investimentos - Como administrar melhor seu dinheiro. São Paulo, Fundamento, 2 $2^{\mathrm{a}}$ ed., 168 p. HENDRIKSEN, E.S. e BREDA, M.F.V. 1999. Teoria da Contabilidade. São Paulo, Atlas, 5ª ed., 550 p.

INSTITUTO BRASILEIRO DE GEOGRAFIA E ESTATÍSTICA. Censo demográfico de 2000 - Banco de dados agregados. Disponível em: http://www.sidra.ibge.gov.br, acesso em 14/04/2006.

KONTZ, H. e O'DONNELL, C. 1959. Princípios de Administração. São Paulo, Pioneira, 827 p. LUQUET, Mara. 2002. Guia Valor Econômico de Finanças Pessoais. São Paulo, Globo, 1ํㅡㄹ ed., 144 p. MAXIMIANO, A.C.A. 1995. Introdução à Administração. São Paulo, Atlas, $4^{\mathrm{a}}$ ed., 434 p.

Orçamento familiar. Disponível em: http://financenter.terra.com.br/, acesso em 25/03/2006. SÁ, A.L. 1992. Teoria Geral do Conhecimento Contábil. Belo Horizonte, IPAT/UNA, $264 \mathrm{p}$.

Data de Submissão: 14/12/2007

Data de Aceite: 15/12/2007 